\title{
Lack of interference between IgA-binding proteins and IgA proteases of human pathogenic bacteria
}

\author{
L. STENBERG, J. QIU*, G. LINDAHL and A. G. PLAUT* \\ Department of Medical Microbiology, Lund University, Sölvegatan 23, S-223 62 Lund, Sweden and *Division of \\ Gastroenterology, Department of Medicine, Tufts - New England Medical Center Hospital, Boston, MA 02111, \\ USA
}

\begin{abstract}
Some human bacterial pathogens produce specific immunoglobulin A1 (IgA1) proteases that cleave the heavy chain of human IgA1, generating intact Fab and Fc fragments. Other pathogenic bacterial species express surface proteins which bind to the Fc part of human IgA in a non-immune manner. To analyse whether IgA-binding proteins affect the activity of IgA1 proteases, the ability of seven different IgA1 proteases to hydrolyse IgA1 in the presence of either of two different bacterial IgA-binding proteins was tested. Data obtained in two different types of experiment suggest that IgA1 bound to IgAbinding proteins still functions as a substrate for IgA1 proteases. As Fc fragments produced by cleaving IgA1 with IgA1 proteases still bind to IgA-binding proteins, we conclude that these two types of bacterial protein act independently of each other.
\end{abstract}

\section{Introduction}

Since the first description of an IgA protease produced by Streptococcus sanguis, several clinically important human pathogens that colonise and infect human mucosal surfaces have been reported to produce specific IgA1 proteases [1]. The three leading causative agents of bacterial meningitis (Neisseria meningitidis, $S$. pneumoniae and Haemophilus influenzae) all produce IgA1 proteases, whereas closely related, non-pathogenic species do not $[2,3]$. Other clinically important bacteria known to produce IgAl proteases include $N$. gonorrhoeae, some oral streptococci and some Bacteroides and Ureaplasma spp. [1,2]. The IgA1 proteases expressed by these bacteria share the ability to hydrolyse one of the peptide bonds in a duplicated octapeptide present in the hinge region of the $\alpha 1$ heavy chain. As the $\alpha 2$ chain lacks this amino-acid sequence, it is resistant to hydrolysis by IgAl proteases. Except for the autocatalytic activity exhibited by some $\operatorname{IgA} 1$ proteases, IgAl from man and a few other primates is the only known substrate for IgAl proteases [1]. However, the IgAl proteases constitute a structurally diverse group of molecules. The nucleotide sequences of the IgA1 protease genes (iga) of $N$. meningitidis, $N$. gonorrhoeae and $H$. influenzae are homologous [4] and

Received 12 Dec. 1994; revised version accepted 11 July 1995.

Corresponding author: L. Stenberg. code for large, $106-108-\mathrm{kDa}$, proteins [5, 6], but these proteins show considerable differences with regard to molecular and serological properties [7]. The reported sequence for the iga gene of $S$. sanguis codes for a 190-kDa protein and shows no similarity to iga genes from gram-negative bacteria [8]. Furthermore, the gene fails to hybridise the chromosomal DNA from $S$. pneumoniae [9].

Another way for human pathogens to interact with IgA is to express surface proteins that bind to the Fc part of IgA in a non-immune manner. Such proteins are expressed by many strains of $S$. pyogenes and by some strains of $S$. agalactiae [10]. Two of the IgA-binding proteins expressed by $S$. pyogenes have been extensively characterised with regard to immunochemical properties-protein Sir that binds both IgA and IgG, and protein Arp that preferentially binds IgA $[10,11]$. The overall structure of these IgA-binding proteins is similar; they have molecular masses of $37-45 \mathrm{kDa}$ [11-13] and they are members of the $M$ protein family [14]. In contrast, the IgA-binding $124-\mathrm{kDa}$ protein expressed by $S$. agalactiae (designated protein Bac or the $\beta$ antigen) is immunologically and structurally unrelated to the IgA-binding proteins of $S$. pyogenes $[10,15]$. Although protein Bac has been shown to bind almost exclusively to serum IgA and not to secretory IgA [15], this IgA-binding protein was included in the present study as protein Bac is structurally unrelated to the IgA-binding proteins of $S$. pyogenes. 
Bacterial species expressing IgA-binding proteins do not produce IgA proteases [2], and no IgA1 proteasepositive bacteria are known to produce IgA-binding proteins of Arp or Bac type. However, bacteria that express $\operatorname{IgA}$ proteases and bacteria that express IgA-binding proteins are commonly found simultaneously in the upper respiratory tract [16]. Therefore, it was of interest to analyse whether these large bacterial proteins interact, as they are produced by major human pathogens. Previously reported results had shown that the bacterial IgA-binding proteins bind to purified Fcfragments produced by digestion with an $\operatorname{IgA}$ protease $[10,17]$, but this finding did not exclude the possibility that the IgA-binding proteins might interfere with the action of IgA proteases. Furthermore, it was of interest to analyse the purified IgA-binding proteins for protease activity.

\section{Materials and methods}

\section{IgAl proteases and IgA-binding proteins}

Seven different IgAl proteases were tested: the enzymes from $S$. sanguis, $S$. pneumoniae, the type 1 and type 2 enzymes from $H$. influenzae and $N$. meningitidis and the type 2 enzyme from $N$. gonorrhoeae. The proteases were purified as described previously [18]. Protein Sir, the IgA- and IgG-binding protein expressed by a group A streptococcal strain of serotype M22, was purified after expression in Escherichia coli as described previously [11]. Protein Bac was purified from a group B streptococcal type Ib strain as described previously [15]. Protein G (CalbiochemNovabiochem, San Diego, CA, USA), an IgG-binding protein originating from the group $\mathrm{G}$ streptococcus, was used as a control. The IgA used as substrate in this study was the monoclonal IgAl (Mor) protein [19], which was ${ }^{125} \mathrm{I}$-labelled by the chloramine- $\mathrm{T}$ method [20]. Proteins Sir and Bac are known to bind a majority of human monoclonal IgA proteins (ref. 11 and our unpublished data). To confirm that these proteins bind to IgAl(Mor), proteins Sir and Bac were separated by SDS-PAGE, transferred to a polyvinylidene difluoride (PVDF) membrane (Immobilon-P; Millipore Corp., Bedford, MA, USA) and incubated with ${ }^{125} \mathrm{I}-\mathrm{IgA} 1$ (Mor). Both bacterial proteins reacted strongly with the probe, whereas the IgG-binding protein $G$ lacked reactivity in a similar way (data not shown).

\section{$\operatorname{Ig} A$ protease assays}

The soluble phase assays were performed at room temperature with mixtures of ${ }^{125} \mathrm{I}-\mathrm{IgA}$, antibody binding protein, and diluted enzyme in $20 \mathrm{mM}$ Tris-buffer, $\mathrm{pH}$ 7.2, supplemented with $10 \mu \mathrm{M} \mathrm{MgCl}_{2}$ and $10 \mu \mathrm{M}$ $\mathrm{CaCl}_{2}$ in the assays with proteases from gram-positive bacteria. To allow binding of $\operatorname{IgA}$ to $\operatorname{IgA}$-binding protein, $15 \mu \mathrm{l}$ of ${ }^{125} \mathrm{I}-\mathrm{IgA}(0.5 \mu \mathrm{g})$ was pre-incubated with $15 \mu \mathrm{l}$ of IgA-binding protein $(0.6 \mu \mathrm{g}$ of $\mathrm{Sir}$ or $1.5 \mu \mathrm{g}$ of Bac, i.e., four-to-five-fold molar excess of
IgA-binding protein), control protein (protein $G$, $0.6 \mu \mathrm{g}$ ) or buffer for $1 \mathrm{~h}$ at room temperature. After this pre-incubation, $15 \mu$ l of enzyme in solution was added, and samples of the reaction mixture were removed at different time points. The reactions were stopped by the addition of sample buffer (SDS $2 \%$ and 2-mercaptoethanol 5\%) and the samples were boiled for $5 \mathrm{~min}$. The assay was performed with two incubation times and with at least two different enzyme concentrations for each enzyme. The samples were separated by SDS-PAGE in acrylamide $12 \%$ gels and the gel was dried and subjected to autoradiography and phosphor imaging (Molecular Dynamics, Sunnyvale, CA, USA) to allow quantification of radioactivity.

In the second type of assay, immobilised pre-formed complexes of IgA-binding protein and ${ }^{125} \mathrm{I}-\mathrm{IgA}$ were digested with different IgA1 proteases. Proteins Sir $(8 \mu \mathrm{g})$, Bac $(4 \mu \mathrm{g}), \mathrm{G}(8 \mu \mathrm{g})$ or ${ }^{125} \mathrm{I}-\mathrm{IgA}(0.4 \mu \mathrm{g})$ were immobilised on a PVDF membrane, and the membranes were blocked and washed with PBS supplemented with Tween $200.25 \%$ and gelatin $0.25 \%$, and incubated with ${ }^{125} \mathrm{I}-\mathrm{IgA}$ for $16 \mathrm{~h}$ at $8^{\circ} \mathrm{C}$. After incubation, the membranes were washed four times for 20 min each with PBS supplemented with Tween $0.25 \%$, gelatin $0.25 \%, 1 \mathrm{M} \mathrm{NaCl}$ and $10 \mathrm{mM}$ EDTA. Eight identical membranes were prepared and each membrane was incubated for $5 \mathrm{~h}$ at room temperature with one of the seven enzymes tested, or with buffer alone. After incubation, the membranes were washed and dried, and the radioactivity was quantified by phosphor imaging.

\section{Results}

The potential interference of IgA-binding proteins with the activity of IgA1 proteases was tested in a standard assay. In different experiments the incubation times and the amount of enzyme used was varied, allowing complete or only partial cleavage of the $\alpha$ chain. The enzymic activity of the protease was not affected by the presence of IgA-binding protein in any of these experiments. Fig. 1 shows the result of a representative experiment in which the effect of the IgA-binding proteins $\mathrm{Sir}$ and Bac was analysed, with the IgGbinding protein $\mathrm{G}$ as control. Inspection of the autoradiographs revealed no differences in the amount of cleaved fragment produced in the absence or presence of IgA-binding proteins. The amount of radioactivity in the bands representing the uncleaved and the cleaved $\alpha$ chain was quantified by phosphor imaging, and the ratio of the two values (cleaved:uncleaved) was used as an estimate of protease activity. The results showed that the cleavage reaction was equally efficient in the presence of protein $\mathrm{Sir}, \mathrm{Bac}$ or $\mathrm{G}$ as when buffer alone was added. Only the reaction with $N$. gonorrhoeae enzyme type 2 in low concentration showed a slight inhibitory effect $(25 \%$ lower ratio than in control; data not shown). Similar results were 

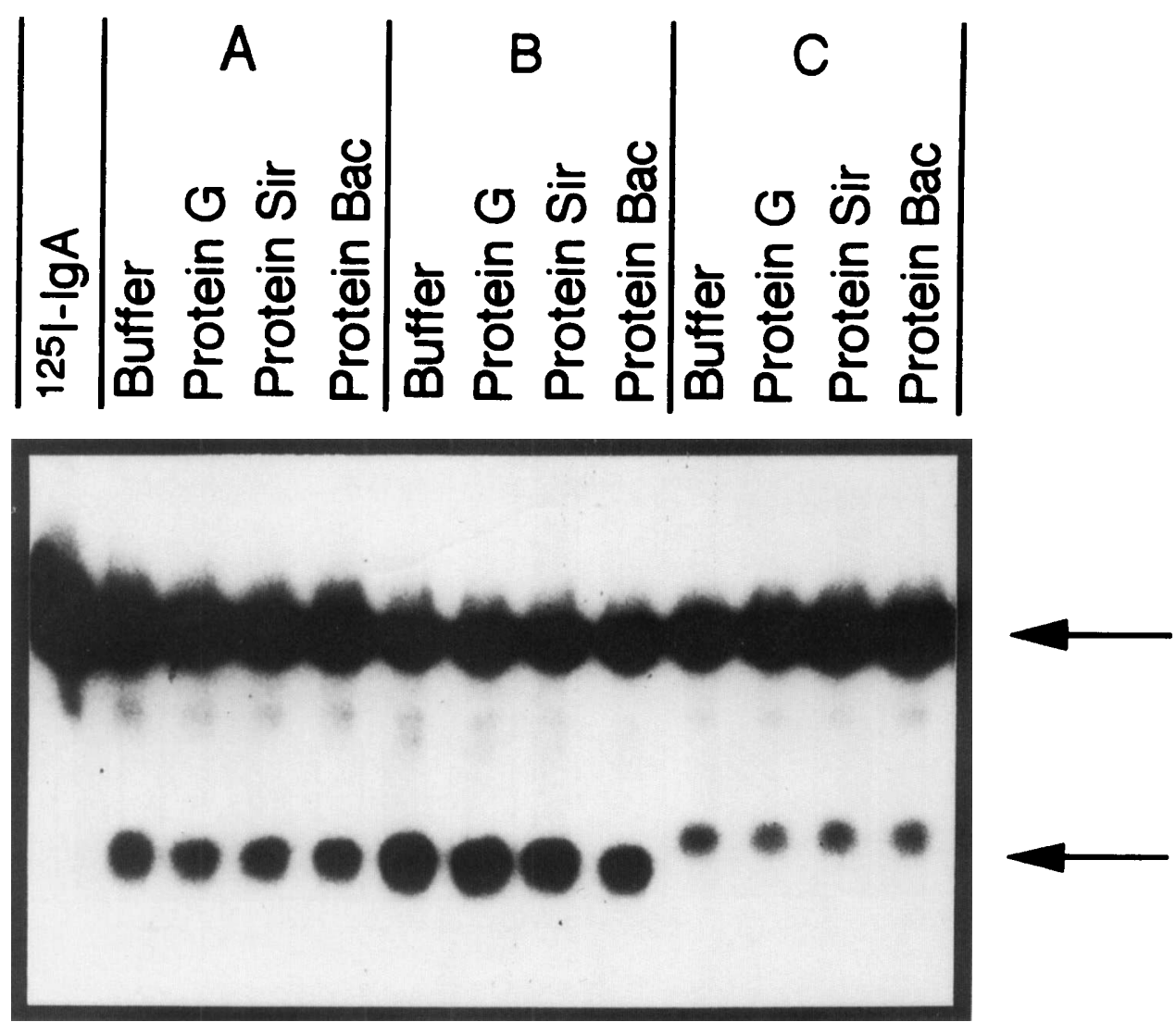

Fig. 1. Effect of bacterial IgA-binding proteins on the activity of IgA1 proteases. Mixtures of ${ }^{125} \operatorname{I-IgA}$, IgA1 protease and IgA-binding protein were incubated for $1 \mathrm{~h}$ at room temperature before separation by SDS-PAGE. After separation, the gel was dried and subjected to autoradiography. The reactions analysed on this gel were designed to allow only partial digestion of the $\alpha 1$ chain. Letters indicate the enzyme used: A, S. sanguis IgA1 protease; B, S. pneumoniae IgA1 protease; C, $H$. influenzae IgA1 protease type 1 . The IgA-binding protein (or control) used is indicated above each lane. The lane marked ${ }^{125} \mathrm{I}-\mathrm{IgA}$ contains uncleaved ${ }^{125} \mathrm{I}-\mathrm{IgA}$. The positions of uncleaved $\alpha 1$ chain (upper arrow) and an $\mathrm{NH}_{2}-$ terminal fragment of the $\alpha 1$ chain (lower arrow) are indicated.

obtained when the IgA-binding protein Arp [10] was used as potential inhibitor (data not shown). These results clearly indicate that pre-incubation of ${ }^{125} \mathrm{I}-\mathrm{IgA}$ with an IgA-binding protein does not affect the ability of IgA proteases to cleave the IgA.

In the experiment shown in Fig. 1, IgA-binding proteins were present in a four-to-five-fold excess as compared to IgA-Fc. Since the binding of IgA to protein Sir and protein Bac is of high affinity $[11,15]$, it is unlikely that the ${ }^{125} \mathrm{I}-\mathrm{IgA}$ digested was present in free, non-bound from. However, an experiment was also designed to analyse whether pre-formed complexes between IgA and IgA-binding proteins are sensitive to proteases. In this experiment, complexes formed on a membrane were used as the substrate (Fig. 2). Protein Sir and protein Bac were immobilised in a row of dots on a strip of PVDF membrane. After blocking and incubation with ${ }^{125} \mathrm{I}-\mathrm{IgA}$, the sensitivity to IgAl protease of ${ }^{125} \mathrm{I}-\mathrm{IgA}$ bound via protein $\mathrm{Sir}$ or protein Bac was analysed. Eight identical membrane strips were prepared and seven of these were incubated with different $\operatorname{IgA}$ proteases and one was incubated with buffer alone. The amount of enzyme added was expected to give $75-100 \%$ digestion of IgA in solution. After incubation, the filters were washed and dried, and the amount of radioactivity remaining in the dots was quantified by phosphor-imaging radiography. The radioactivity in the control dots (membrane incubated with buffer alone) was compared with the radioactivity in the dots on the membranes digested with various enzymes. The complexes of IgA-binding protein and IgA were sensitive to cleavage, as the amount of radioactivity was reduced on all filters incubated with enzyme, as compared to the filter incubated with buffer alone. As $c .10 \%$ of the radioactivity of the ${ }^{125} \mathrm{I}$-IgA1(Mor) molecule is located on the Fc part [19], cleavage of all IgA molecules would result, theoretically, in a $90 \%$ reduction of radioactivity. However, radioactivity was not reduced to this extent, which may be explained by reduced activity of the IgAl proteases close to the PVDF membrane. In an attempt to estimate the activity of the IgA1 protease under the experimental conditions used in Fig. 2, the activity of the protease on ${ }^{125} \mathrm{I}-\mathrm{IgA}$ immobilised directly to the membrane was also determined (Fig. 2 , black bars). The $H$. influenzae type 1 enzyme, which was the least efficient in cleaving IgA that had bound to immobilised IgA-binding proteins, was also the least efficient in cleaving IgA immobilised directly 


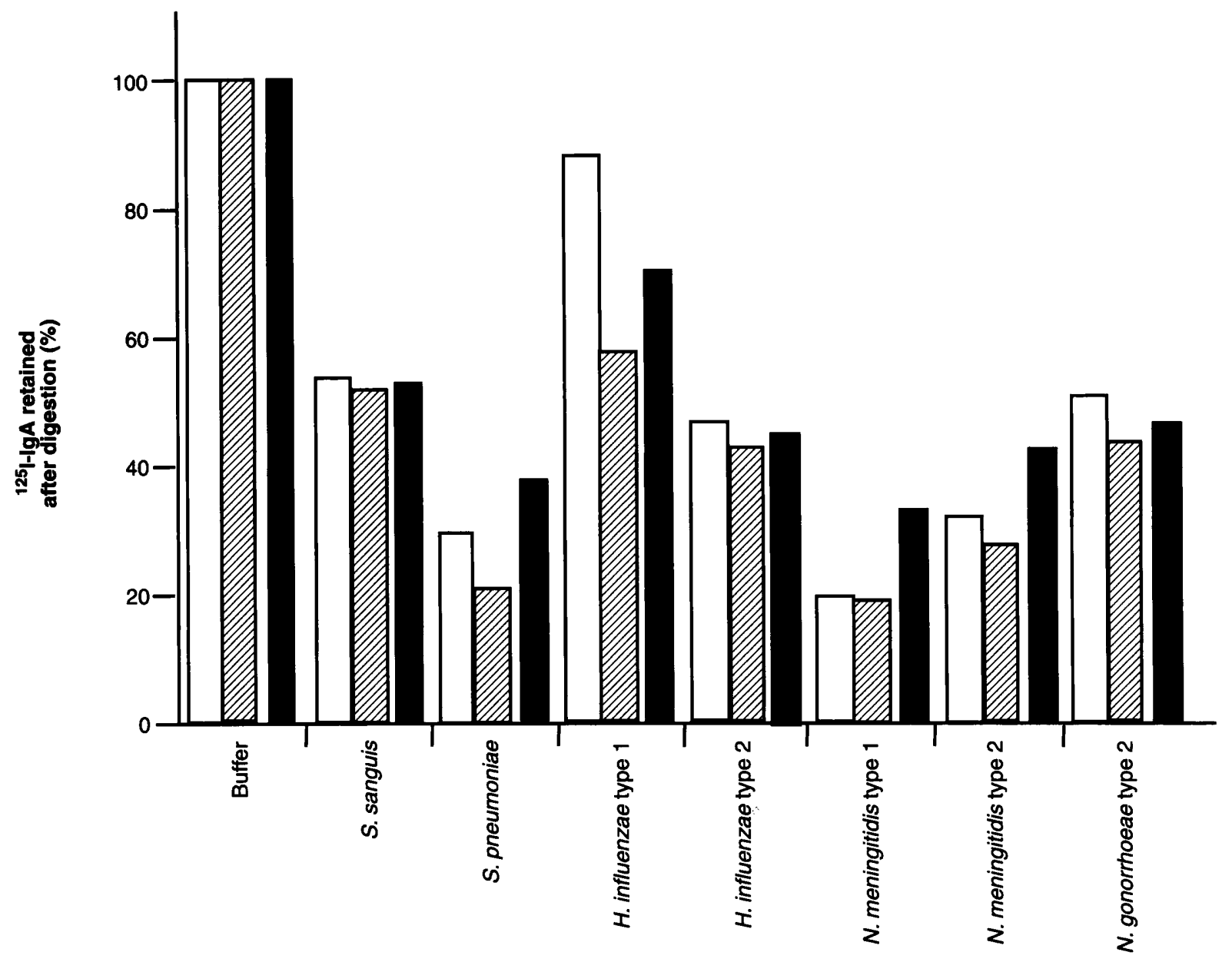

Enzyme

Fig. 2. Effect of IgA1 proteases on pre-formed complexes between $\operatorname{IgAl}$ and IgA-binding proteins. ${ }^{125} \mathrm{I}-\mathrm{IgA}$ was immobilised on PVDF membrane strips via membrane-bound protein Sir ( $\square$ ) or protein Bac ( $\triangle$ ). A series of identical strips was incubated with different IgAl proteases or with buffer alone. The vertical bars show the amount of radioactivity retained after incubation with these enzymes. The amount of radioactivity on the membrane treated with buffer alone was defined as $100 \%$. The activity of the different IgAl proteases on ${ }^{125} \mathrm{I}-\mathrm{IgA}$ immobilised directly to the PVDF-membrane was also determined (ם) to estimate the activity of the different proteases under these experimental conditions.

to the membrane, suggesting that the PVDF membrane had an inhibitory effect on the protease activity. Nevertheless, the data in Fig. 2 show that a large fraction of the ${ }^{125} \mathrm{I}-\mathrm{IgA}$ bound to IgA-binding proteins was sensitive to the action of the different IgAl proteases, which indicated that the IgA-binding proteins did not interfere with the activity of $\operatorname{IgAl}$ proteases.

To analyse whether the IgA-binding proteins, Sir, Arp or Bac had any IgA protease activity, these proteins were analysed in the $\operatorname{IgA}$ protease assay, with incubation times from $30 \mathrm{~min}$ to $4 \mathrm{~h}$, and incubation temperatures of $37^{\circ} \mathrm{C}$ or $23^{\circ} \mathrm{C}$. Samples were separated on SDS-PAGE and analysed by phosphor imaging as described above. In all cases, the ${ }^{125} \mathrm{I}-\mathrm{IgA}$ used as substrate was not degraded by the presence of the $\operatorname{IgA}$ binding proteins (data not shown). Furthermore, proteins Sir and Bac were shown to be resistant to the $S$. sanguis and $H$. influenzae type $2 \mathrm{IgAl}$ proteases (not shown).

\section{Discussion}

The production of $\operatorname{IgA}$ in man exceeds that of all other Ig classes combined [21]. Most of this IgA is found in secretions on mucosal surfaces, where it plays an important role in defence against pathogenic microorganisms by virtue of its antigen-binding capacity. However, many pathogens interact with IgA by secreting highly specific IgAl proteases $[1,3]$, and other bacteria express surface proteins capable of binding to the Fc part of IgA [10]. The biological role of these large bacterial proteins is not fully understood, but they are generally believed to be important for microbial virulence. The object of this study was to determine whether bacterial IgA1 proteases and IgAbinding proteins act independently on the IgA molecule.

Two different types of experiment were used, in which IgA substrate was complexed with IgA-binding proteins in solution, or immobilised on membranes. When ${ }^{125}$ I-IgA was pre-incubated with either IgA- 
binding protein or buffer prior to digestion with different IgA1 proteases, the enzymes were found to be equally active in the presence or absence of IgAbinding proteins, as determined by analysis of the cleaved fragments on SDS-PAGE. In the other type of experiment, complexes of IgA-binding proteins and ${ }^{125} \mathrm{I}$-IgA were immobilised on a membrane. Incubation with various IgAl proteases reduced the amount of radioactivity on the membrane, indicating that the complexed ${ }^{125} \mathrm{I}-\mathrm{IgA}$ still functioned as a substrate for IgA1 protease. Taken together, these results indicate that IgA1 proteases and IgA-binding proteins, despite their large sizes, do not sterically interfere with each other; specifically, IgA-binding proteins fail to block access of proteases to the susceptible IgAl hinge region peptide bonds. Furthermore, these results show that purified IgA-binding proteins lack IgA protease activity. Therefore, human bacterial pathogens colonising mucosal surfaces have developed two unrelated ways to interact with $\operatorname{IgA}$, which underlines the importance of IgA in the defence against pathogens on mucosal surfaces.

Part of this work was done by L. S. in the laboratory of A. G. Plaut. Financial support came from the Medical Faculty of Lund University, the Swedish Society for Medical Research, the Royal Physiographic Society, Lund, US Public Health Service-NIH grant DE 09677 and the GRASP Digestive Disease Research Center, NIH DK-34928.

\section{References}

1. Senior BW, Loomes LM, Kerr MA. Microbial IgA proteases and virulence. Rev Med Microbiol 1991; 2: 200-207.

2. Kilian M, Thomsen B, Petersen TE, Bleeg HS. Occurrence and nature of bacterial IgA proteases. Ann NY Acad Sci 1983; 409: 612-624.

3. Plaut AG. The IgAl proteases of pathogenic bacteria. Annu Rev Microbiol 1983; 37: 603-622.

4. Koomey JM, Falkow S. Nucleotide sequence homology between the immunoglobulin A1 protease genes of Neisseria gonorrhoeae, Neisseria meningitidis, and Haemophilus influenzae. Infect Immun 1984; 43: 101-107.

5. Pohlner J, Halter R, Beyreuther K, Meyer TF. Gene structure and extracellular secretion of Neisseria gonorrhoeae IgA protease. Nature 1987; 325: 458-462.
6. Poulsen K, Brandt J, Hjorth JP, Thøgersen HC, Kilian M Cloning and sequencing of the immunoglobulin Al protease gene (iga) of Haemophilus influenzae serotype b. Infect Immun 1989; 57: 3097-3105.

7. Lomholt $\mathrm{H}$, Kilian M. Antigenic relationships among immunoglobulin A1 proteases from Haemophilus, Neisseria, and Streptococcus species. Infect Immun 1994; 62: 3178-3183.

8. Gilbert JV, Plaut AG, Wright A. Analysis of the immunoglobulin A protease gene of Streptococcus sanguis. Infect Immun 1991; 59: 7-17.

9. Gilbert JV, Plaut AG, Fishman Y, Wright A. Cloning of the gene encoding streptococcal immunoglobulin A protease and its expression in Escherichia coli. Infect Immun 1988; 56: 19611966.

10. Lindahl G, Hedén L-O, Stenberg L. Streptococcal IgA receptors. In: Korhonen TK, Mäkelä $\mathrm{PH}$, Hovi $\mathrm{T}$ (eds) Molecular recognition in host-parasite interactions. New York, Plenum Press, 1992: 77-83.

11. Stenberg L, O'Toole PW, Mestecky J, Lindahl G. Molecular characterization of protein Sir, a streptococcal cell surface protein that binds both Immunoglobin A and Immunoglobin G. J Biol Chem 1994; 269: 13458-13464.

12. Frithz E, Hedén L-O, Lindahl G. Extensive sequence homology between IgA receptor and $\mathrm{M}$ proteins in Streptococcus pyogenes. Mol Microbiol 1989; 3: 1111-1119.

13. Hedén L-O, Lindahl $G$. Conserved and variable regions in protein Arp, the IgA receptor of Streptococcus pyogenes. J Gen Microbiol 1993; 139: 2067-2074.

14. O'Toole P, Stenberg L, Rissler M, Lindahl G. Two major classes in the $\mathbf{M}$ protein family in group $\mathrm{A}$ streptococci. Proc Natl Acad Sci USA 1992; 89: 8661-8665.

15. Lindahl G, Ảkerström B, Vaerman J-P, Stenberg L. Characterization of an IgA receptor from group B streptococci: specificity for serum IgA. Eur J Immunol 1990; 20: 22412247.

16. Rosebury T. Distribution and development of the microbiota of man. In: Rosebury T (ed) Microorganisms indigenous to man. New York, McGraw-Hill. 1962: 310-384.

17. Schalén C. The group A streptococcal receptor for human IgA binds via the Fc-fragment. Acta Pathol Microbiol Scand Sect C 1980; 88: 271-274.

18. Bachovchin WW, Plaut AG, Flentke GR, Lynch M, Kettner CA. Inhibition of IgA1 proteinases from Neisseria gonorrhoeae and Haemophilus influenzae by peptide prolyl boronic acids. $J$ Biol Chem 1990; 265: 3738-3743.

19. Plaut AG, Gilbert JV, Leger G, Blumstein M. IgA1 protease cleaves heavy chains independently in dimeric human IgA1. Mol Immunol 1985; 22: 821-826.

20. Greenwood FC, Hunter WM, Glover JS. The preparation of $\left.{ }^{125} \mathrm{I}\right)$-labelled human growth hormone of high specific radioactivity. Biochem $J$ 1963; 89: 114-123.

21. Kilian M, Mestecky J, Russell MW. Defense mechanisms involving $\mathrm{Fc}$-dependent functions of immunoglobulin $\mathrm{A}$ and their subversion by bacterial immunoglobulin A proteases. Microbiol Rev 1988; 52: 296-303. 